\title{
Principles of the distribution of wheat with fusariois disease, its effect on yield, harm and disease measures in the case of Uzbekistan
}

\author{
$N$ Khaytbayeva $^{1, *}, M$ Sattorova $^{1}, U$ Rakhimov $^{1}$, and $N$ Tillyakhodjaeva $^{2}$ \\ ${ }^{1}$ Tashkent State Agrarian University, University str., 2, Tashkent province, 100140 Uzbekistan \\ ${ }^{2}$ Scientific Research Institute of Plant Protection, Tashkent, Uzbekistan
}

\begin{abstract}
This paper shows the role of Fusarium fungi in the farms of Kibray district of Tashkent province, which cause sudden yellowing of wheat fields before ripening, reducing the symptoms of the disease and the yield. The amount of grain in a diseased plant is reduced by $42 \%$ compared to the grain in a healthy plant, and the weight is reduced by $57.1 \%$. Pure cultures of microorganisms were isolated from samples taken from diseased fields. The article is based on the results of scientific experiments and contains 2 tables and figures. The information presented in the article will serve as a scientific basis for further study of the prevalence and harm of wheat fusarium wilt.
\end{abstract}

\section{Introduction}

The most pressing issue in the fight against plant diseases in the republic is the creation of resistant varieties, the prevention of crop losses on the basis of their introduction into agriculture. Fusarium wilt is a disease that affects grain yield and grain quality in many parts of the world $[1,3]$.

In the southern provinces of Russia, $20-50 \%$ of crops die due to this disease, which began to spread in 1980 [1,2]. The problem of fusarium wilt in cereals is an international issue. Their prevalence on Earth, their variability, the problem of many plant diseases, compels many professionals to turn to this issue to maintain human and animal health [2, 3].

One of the most effective ways to get a good harvest from grain crops is to protect plants from disease, insects and weeds [3,5]. All agricultural crops in their ontogenesis interact differently with microorganisms in the soil, water and air. This process also affects the activity and passivity of all organisms in the agrophytocenosis, depending on environmental conditions [4, 8-10].

Changes in the activity of soil microorganisms in wheat fields are also negatively affected by the process of regular sowing of the same crop in the same field for years, as well as the process of incorrect selection of inter-crop crops. As a result, the activity of microorganisms in the soil changes, leading to a change in their role in the food chain $[6$,

\footnotetext{
* Corresponding author: khaytbayevanodira@,mail.ru
} 
7]. Due to the fact that this process is especially noticeable in the world of fungi, the activity of some pathogenic species is declining, and the activity of some facultative parasitic fungi is increasing [1].

For example, the prevalence of fusarium wilt since 2000 instead of the verticillium wilt of cotton, which was common in 1970-1990, is due to the expansion of the species composition of the host plants they parasitize. The main reason for this is the emergence of aggressive breeds with new physiological and biochemical properties as a result of crossbreeding of populations of fungi in the soil, which allows them to form and spread a new habitat [1-4].

Such breeds of fusarium wilt, which cause Fusarium wilt, are found in wheat agrobiocenosis in almost all provinces of the Republic. Aggressive forms of wheat disease in the Tashkent province prove the emergence of new races among the representatives of this group. As a result, new racial populations have been observed to infect cotton or wheat in a small area with widespread soils $[2,6,10]$.

Due to the fact that the level of tolerance of wheat varieties grown in these populations has not been scientifically studied, the manifestation of the symptoms of the disease, the damage has not been fully determined [1-4, 6, 7]. In limiting the spread of the disease and developing scientifically based control measures against it, the study of the species composition of the fungal community in the soil, the correct determination of the phytosanitary condition of the field allows to scientifically substantiate the preservation of immune properties of agricultural crops.

\section{Materials and methods}

Fusarium wilt of agricultural crops is one of the most interesting but most difficult species to study among crop diseases. One of the main reasons for the relatively weak study of Fusarium fungi in our country is the rapid variability of its morphological features and the extreme difficulty of identifying species. Most importantly, the lack of identifiers for the taxonomy of the Fusarium fungus [1,3], or a sharp decline in their numbers, presents specific difficulties in their study [4, 7].

This fungus has been studied in the Republic of Uzbekistan for more than 70 years. Species belonging to the family Fusarium are among the most common fungi in the soil, plants, air and water of the Republic. They live in the rhizosphere of higher plants and infect various plants, weeds, insects, nematodes. Participates in the process of soil formation in the extreme conditions of the country, actively participates in the balance of the food chain, the decomposition of plant residues. Enzymes produced by species of Fusarium fungi that live in the soil play an important role in the breakdown of animal and insect remains, the synthesis of organic, biologically active substances. In the study of fusarium wilt, Litvinov's (1969) method was used to isolate microorganisms from the soil, and VI Bilay (1977) was used to identify isolated fungal species [1-4, 6, 7].

\section{Results and discussion}

The distribution of populations of new aggressive breeds of fungi belonging to the genus Fusarium in a limited area was studied. Infection of wheat by these fungi was observed in farms located in the village of Baytkurgan, Tashkent province. Sudden yellowing of wheat was observed in areas with a total area of $10-15 \mathrm{~m}^{2}$, and in some areas with an area of 20$25 \mathrm{~m}^{2}$ (Fig. 1). 


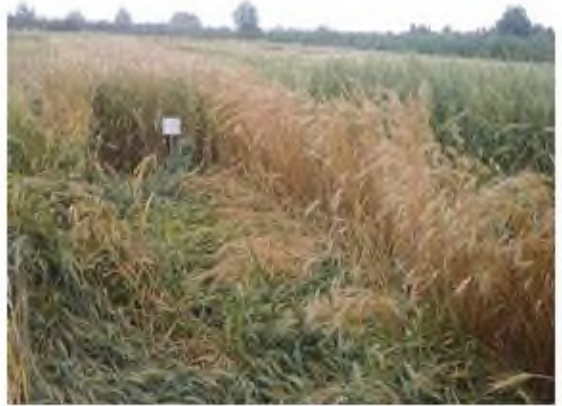

Wheat field infected with fusarium wilt

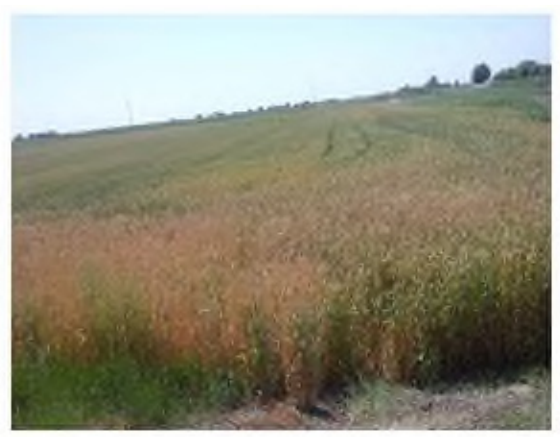

Outbreaks appear to be exacerbated during

fusarium wilt

Fig. 1. Outbreaks of fusarium wilt in wheat fields on a farm in Kibray district of Tashkent province.

Diseased plants begin to turn yellow and dry out in small areas before they are fully ripe. The root system of the diseased plant turns dark brown, the stem becomes thinner, and the area around the joint can be seen to turn dark brown. The spikes formed on such stems are smaller than a healthy plant, the grains begin to dry before ripening, the shape is small, the grain surface is rough. The weight of diseased grains decreases sharply and becomes useless (Fig. 2). Due to the disease, the germination of seeds decreases, the plant roots rot, wither and the grains in the ears become ill.

During the mycological analysis, 7 species of Fusarium fungi were identified from soil samples taken from the diseased fields, and Fusarium, Penicillium, and Alternaria fungi were isolated from the seeds, stems and roots of the infected plants. The future study of the relationship of fungi belonging to this family with diseased plants and species belonging to the family Fusarium is of great theoretical and practical importance in the development of biological control strategies against the disease.

Fusarium wilt of wheat not only reduces grain yield, but also has a negative effect on grain quality (Table 1).

From the data in the table, it can be seen that the weight of 570 grains of wheat from a bunch of healthy wheat stalks is 35 grams at the time of analysis. The number of grains in the diseased plant is 325 , weighing 20 grams. As a result, the amount of grain in a diseased plant is reduced by $42 \%$ compared to the grain in a healthy plant, and the weight is reduced by $57.1 \%$. 


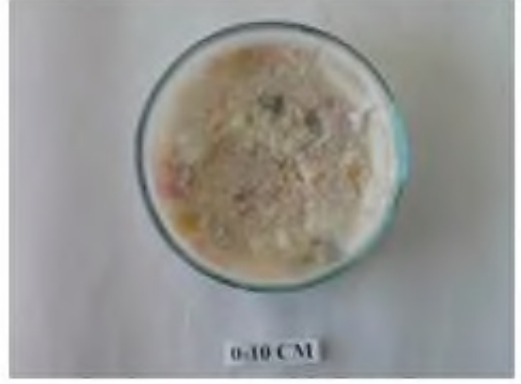

Microorganisms isolated from the soil taken from a depth of $0-10 \mathrm{~cm}$ in a wheat field

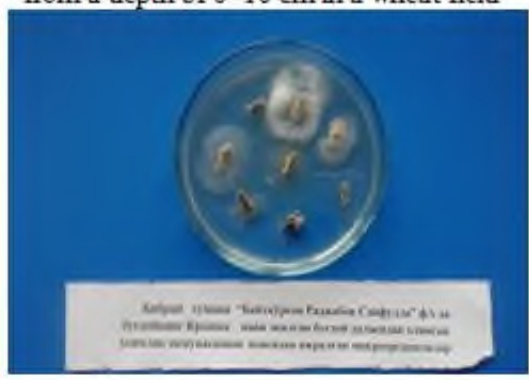

Microorganisms isolated from the stalks of wheat infected with fusarium wilt

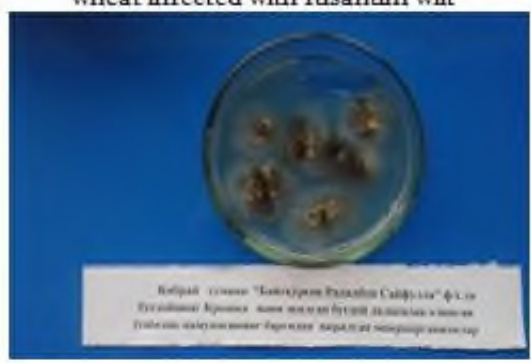

Microorganisms isolated from the leaves of wheat infected with fusarium wilt

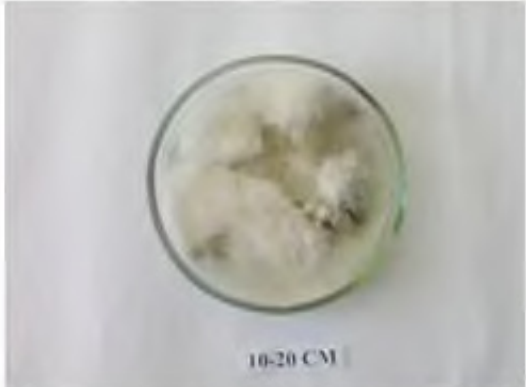

Microorganisms isolated from the soil taken from a depth of $10-20 \mathrm{~cm}$ in a wheat field

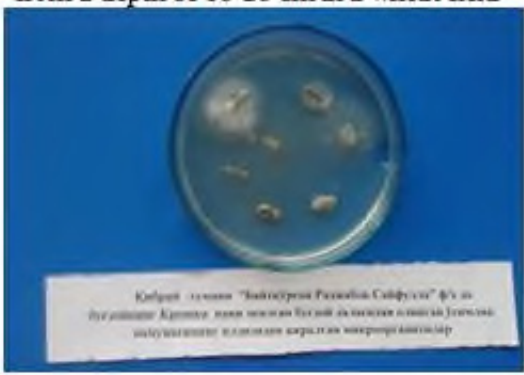

Microorganisms isolated from the root of wheat infected with fusarium wilt

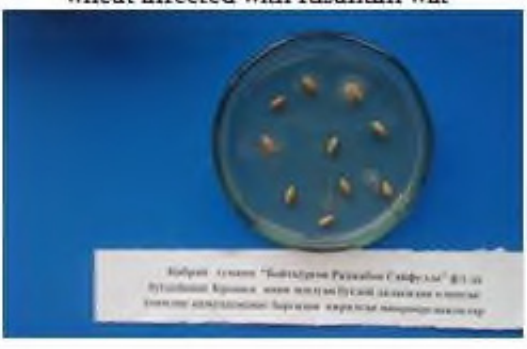

Microorganisms isolated from wheat grains infected with fusarium wilt

Fig. 2. Laboratory analysis of soil and plant samples from fields where fusarium wilt prevalence.

Table 1. Decrease in number and weight of grains in healthy and diseased wheat stalks

\begin{tabular}{|c|c|c|c|c|}
\hline \multirow{4}{*}{ Plant state } & \multicolumn{2}{|c|}{ In a bush } & \multicolumn{2}{c|}{ Decrease in grain quantity, \% } \\
\cline { 2 - 5 } & $\begin{array}{c}\text { Number of } \\
\text { grains }\end{array}$ & Grain weight, gr & \multicolumn{2}{c|}{} \\
\cline { 3 - 5 } & 570 & 35 & 0 & weight \\
\hline Healthy & 325 & 20 & 42 & 57.1 \\
\hline Diseased & & & & \\
\hline
\end{tabular}

The following table shows the number of grains in each grain and their weight. As the shape and development of the grains are delayed due to the disease, their shape crumbles and their weight decreases sharply (Table 2). 
Table 2. The weight of grains formed in the ears of healthy and diseased wheat stalks

\begin{tabular}{|c|c|c|c|c|c|c|}
\hline \multirow{2}{*}{ Pods } & \multicolumn{2}{|c|}{$\begin{array}{c}\text { Number of healthy } \\
\text { grains }\end{array}$} & \multicolumn{2}{c|}{$\begin{array}{c}\text { Number of diseased } \\
\text { grains }\end{array}$} & \multicolumn{2}{c|}{ Reduction of yield } \\
\cline { 2 - 7 } & $\#$ & Weight, g & $\#$ & Weight, g & $\#$ & Weight, g \\
\hline Pod 1 & 47 & 13 & 28 & 3 & 19 & 10 \\
\hline Pod 2 & 50 & 14 & 41 & 7 & 9 & 7 \\
\hline Pod 3 & 46 & 12 & 41 & 6 & 5 & 7 \\
\hline Pod 4 & 47 & 14 & 13 & 2 & 34 & 12 \\
\hline Pod 5 & 47 & 13 & 39 & 7 & 8 & 6 \\
\hline Pod 6 & 48 & 14 & 4 & 1 & 44 & 13 \\
\hline Pod 7 & 48 & 13 & 27 & 3 & 21 & 10 \\
\hline Pod 8 & 48 & 12 & 33 & 4 & 15 & 8 \\
\hline Pod 9 & 47 & 14 & 18 & 5 & 29 & 9 \\
\hline Pod 10 & 46 & 13 & 21 & 3 & 25 & 10 \\
\hline Average & 47.5 & 13.2 & 27.5 & 4.1 & 20 & 9.2 \\
\hline
\end{tabular}

Thus, the optional parasite in the soil caused by the drying of grains in wheat fields before the grains ripen is caused by representatives of the fungus Fusarium family.

Based on the study of morphological, biological, biochemical, physiological, genetic properties of these fungi, scientists around the world have conducted a number of studies aimed at limiting their number in the agrobiocenosis, reducing their damage.

This problem is the focus of international organizations such as FAO, WHO, UNEP, because the toxins produced by the fungus in plants also affect human and animal health.

\section{Conclusions}

Measures to organize the fight against wheat fusarium wilt should be carried out in the following three areas:

The first direction is to conduct fundamental research to study the morphological, biological, biochemical, physiological, genetic characteristics of the fungus Fusarium in the extreme conditions of the country;

Secondly, for the scientific organization of the fight against the disease, it is necessary to take into account the characteristics of the fungus in the soil under the conditions of crop rotation;

Treatment with fungicides against fusarium wilt in preparation of seeds for sowing;

Thirdly, it is necessary to carry out agro-technical measures such as deep plowing of grain-free fields, eradication of weeds and plant residues in the field, maintenance of seed moisture, preparation of seeds from yellow seeds, application of mineral and organic fertilizers to crops.

The development of a scientific basis for reducing the harm of wheat fusarium wilt is of great theoretical and practical importance. Disease control measures should include presowing seed treatment, during the growing season, and after harvest. Due to the fact that the grain-growing provinces of the country are geographically and ecologically diverse from north to south, it is impossible to recommend a single control measure that reduces the damage of the disease, which is common.

Depending on the magnitude of the impact of technological and biotic factors, the following should be taken into account: what crop to plant wheat after flowering, wheat flowering, moisture content in the crop during the germination phase, tillage system, variety tolerance, general condition of the plant, method of harvesting, post-harvest activities.

Therefore, measures to organize the fight against wheat fusarium wilt should be carried out in the following directions: 
- Carrying out fundamental research to study the morphological, biological, biochemical, physiological, genetic characteristics of the fungus Fusarium in the extreme conditions of the Republic;

- For the scientific organization of the fight against the disease, it is necessary to reveal the laws of the biological properties of the fungus in the soil under the conditions of cottonwheat rotation;

- It is necessary to create a scientific basis for the formation of an artificial community of saprotrophic microorganisms in the seed layer of the soil;

-preparation of seeds from healthy plants, treatment with fungicides that have an effective effect on fusarium wilt before preparing them for planting;

- creation of a scientific system for combating the source of infection in the soil, air and seeds;

- It is necessary to carry out agro-technical measures, such as deep plowing of grain-free fields, application of mineral and organic fertilizers, elimination of weeds and plant residues in the fields, maintenance of moisture in seeds and warehouses.

\section{References}

1. I. Azimjanov, Flora and florium of Central Asia, 151-152 (1992)

2. V. Bilay, Fusarium, 439-441 (1997)

3. V. Bilay, Biological active features of microscopic fungi, 266-269 (1995)

4. M. Mamiev, J. Safiyazov, A. Sheraliev, Struggling with pests and weeds, 69-75 (2005)

5. S. Isaev, S. Khasanov, Y. Ashirov, A. Gofirov, T. Karabaeva, In E3S Web of Conferences, 244, 02047 (2021)

6. A. Sheraliev, A. Elmuradov, Bulletin of Karakalpak Branch of Uzbekistan Academy of Sciences, 1(152), 78-80 (1998)

7. A. Sheraliev, Struggling with pests and weeds, 54-66 (1995)

8. S. K. Isaev, R. U. Rakhmonov, S. S. Tadjiev, G. I. Gozeiv, S. Z. Khasanov, In IOP Conference Series: Earth and Environmental Science, 614(1), 012147 (2020)

9. B. Sh. Matyakubov, Z. J. Mamatkulov, R. K. Oymatov, U. N. Komilov, G. E. Eshchanova, InterCarto, InterGIS, 26, 229-239 (2020)

10. S. Isaev, S. Khasanov, Y. Ashirov, T. Karabaeva, A. Gofirov, In E3S Web of Conferences, 244, 02012 (2021) 